\title{
Clínica psicológica, trabalho e desemprego: considerações teóricas
}

\begin{abstract}
Maria Luísa Sandoval Schmidt
Este artigo faz uma abordagem crítica da separação entre psicologia do trabalho e psicologia clínica, apontando a necessidade de uma articulação, em rede, de fenômenos e conceitos usualmente separados pelas duas áreas como exigência para a constituição de um pensamento e de uma prática clínicos na esfera do trabalho e do desemprego. Explora conceitos da clínica winnicottiana, delineando uma prática de acolhimento às experiências de solidão, desenraizamento, desalojamento e desesperança decorrentes das dificuldades no trabalho e do desemprego. Esta proposição apoia-se, sobretudo, no trabalho de situar-se empreendido pelo cuidador e pelo cliente e na idéia de um setting psicoterápico construído como morada.
\end{abstract}

Palavras-chave: clínica psicológica, trabalho, desemprego, interdisciplinaridade, Winnicott.

$\mathrm{N}$ o artigo O impacto do conceito de cultura sobre o conceito de homem, Clifford Geertz (1989) usa a expressão "estratigráfica" para designar uma concepção das relações entre os fatores biológico, psicológico, social e cultural da vida humana. Segundo essa visão "estratigráfica", o homem seria composto de camadas hierarquicamente sobrepostas, cada qual completa e irredutível a si mesma, objeto de uma disciplina acadêmica independente em sua especificidade. À hierarquia de esferas correspoderia uma hierarquia de disciplinas voltadas à análise do homem. Numa espécie de "empilhamento" analítico, a imagem do homem vai sendo construída.

Retiram-se as variadas formas da cultura e se encontram as regularidades estruturais e funcionais da organização social. Descascam-se estas, por sua vez, e se encontram debaixo os fatores psicológicos - "as necessidade básicas" ou o-que-tem-você - que as suportam e as tornam possíveis. Retiram-se os fatores psicológicos e surgem então os fundamentos biológicos - anatômicos, fisiológicos, neurológicos - de todo o edifício da vida humana. (Geertz, 1989, p. 49).

Com sua costumeira ironia, Geertz explicita, criticamente, uma posição arraigada na especificidade das disciplinas, desdobrada na definição de objetos e métodos exclusivos, que pratica a decomposição do homem, creditando à "natural" complementariedade das áreas sua recomposição num todo. Nessa perspectiva:

O homem era um animal hierarquicamente estratificado, uma espécie de depósito evolutivo, em cuja definição cada nível - orgânico, psicológico, social e cultural - tinha um lugar designado e incontestável. Para ver o que ele realmente era tínhamos que

\footnotetext{
${ }^{1}$ Docente do Departamento de Psicologia da Aprendizagem, do Desenvolvimento e da Personalidade do Instituto de Psicologia da Universidade de São Paulo, Serviço de Aconselhamento Psicológico.
} 
suportar os achados das várias ciências relevantes - antropologia, sociologia, psicologia, biologia - uns sobre os outros como em muitos padrões de moiré (...) (Geertz, 1989, p. $50)$.

Dois efeitos, por assim dizer, dessa visão "estratigráfica" interessam de perto à abordagem do tema aqui proposto, no âmbito da psicologia. O primeiro deles diz respeito ao lugar reservado às outras disciplinas na perspectiva de uma delas: o lugar de pano de fundo. Ou seja, para a psicologia, o cultural, o social ou o biológico podem, quando levados em conta, aparecer como o pano de fundo dos fenômenos psicológicos. $\mathrm{O}$ segundo refere-se à reprodução da estratificação no interior da psicologia, por meio das especificidades das áreas, com suas ressonâncias conceituais e práticas.

Pela lente "estratigráfica", o pensamento clínico-psicológico hegemônico localiza o trabalho e o desemprego no pano de fundo sócio-ecônomico: o desemprego, como fenômeno, é objeto da psicologia do trabalho, da economia, da sociologia e o trabalho - categoria fundamental na definição de homem - é conceito periférico nas teorias e práticas psicoterápicas (Sato \& Schmidt, 2001).

A dificuldade reside, portanto, na articulação de um pensamento e de uma prática que enfrentem a ótica "estratigráfica". Trata-se da proposição de uma interdisciplinaridade que não opere por justaposição, mas por meio de sínteses compreensivas.

Em sua crítica, Geertz sugere este tipo de busca interdisciplinar como via de superação da fragmentação. Ele escreve:

Resumindo, precisamos procurar relações sistemáticas entre fenômenos diversos, não identidades substantivas entre fenômenos similares. E para consegui-lo com bom resultado precisamos substituir a concepção "estratigráfica" das relações entre vários aspectos da existência humana por uma sintética, isto é, na qual fatores biológicos, psicológicos, sociológicos e culturais possam ser tratados como variáveis dentro de sistemas unitários de análise (Geertz, 1989, p. 56).

Conectar clínica psicológica, trabalho e desemprego demanda, sem dúvida, um esforço no sentido de articular conceitos de diferentes disciplinas, bem como fenômenos usualmente separados como objetos de diferentes áreas da psicologia num sistema unitário ou numa rede.

Os escritos de D. W. Winnicott, psicanalista inglês, podem contribuir para esta reflexão na medida em que são atravessados pela pergunta sobre em que condições se constitui o sujeito da experiência capaz de articular a libido, as pulsões e o ambiente, o mundo, a cultura (Luz, 1990).

\footnotetext{
${ }^{2}$ Alunos de quinto ano de graduação do Instituto de Psicologia da USP, ao serem indagados sobre as possibilidades de inclusão do desemprego na esfera da psicoterapia, manifestram três tipos de posições: por reconhecer o desemprego como fenômeno sócio-econômico, excluiram o mesmo do campo da psicoterapia; considerando o desemprego como exterior à clínica, supunham, no entanto, a possibilidade de acolhimento dos sentimentos experimentados pelo desempregado; tentavam fugir de um certo "psicologismo", acolhendo os sentimentos do desempregado e, ao mesmo tempo, buscavam referir a experiência emocional deste indivíduo em relação a um ambiente adverso. (Sato \& Schmidt, 2001).
} 
Para Winnicott, a experiência cultural está localizada no espaço transicional ou potencial que, paradoxalmente, une e separa eu e meio-ambiente. (Winnicott, 1975a).

O espaço transicional ou potencial tem suas raízes nos primórdios do desenvolvimento do bebê humano e, tal como concebido por Winnicott, refere-se a uma área de experiência intermediária entre os chamados mundo interno e mundo externo. Nas palavras do autor:

Minha reivindicação é a de que, se existe necessidade desse enunciado duplo (mundo interno, mundo externo), há também a de um triplo: a terceira parte da vida de um ser humano, parte que não podemos ignorar, constitui uma área intermediária de experimentação, para a qual contribuem tanto a realidade interna quanto a vida externa. Trata-se de uma área que não é disputada, porque nenhuma reivindicação é feita em seu nome, exceto que ela exista como lugar de repouso para o indivíduo empenhado na perpétua tarefa humana de manter as realidades interna e externa separadas, ainda que inter-relacionadas (Winnicott, 1975b, p. 15) .

A experimentação à qual o autor faz menção depende da existência de um meioambiente ou uma ambiência psicossocial que, ao mesmo tempo, proteja o bebê de invasões que interrompam a continuidade de ser por ele experimetada e apresente o mundo, através de coisas e pessoas, de modo adequado às suas necessidades. Essa experimentação é constituinte do sentimento simultâneo, para o indivíduo humano, de que ele e o mundo existem, sentimento que tem sua origem na ilusão. Tomando a mãe como "representante" do meio-ambiente ${ }^{4}$, dedicada a cuidar do bebê, Winnicott descreve a ilusão como experiência que une, inicialmente, de maneira positiva, a criança e o mundo humano, sendo a base de um viver criativo. Ele explicita que:

A adaptação da mãe às necessidades do bebê, quando suficientemente boa, dá a este a ilusão de que existe uma realidade externa correspondente à sua própria capacidade de criar. Em outras palavras, ocorre uma sobreposição entre o que a mãe supre e o que a criança poderia conceber. Para o observador, a criança percebe aquilo que a mãe apresenta, mas essa não é toda a verdade. $O$ bebê percebe o seio apenas na medida em que um seio poderia ser criado exatamente ali e naquele então (Winnicott, 1975b, p. 27).

Os objetos e fenômenos transicionais pertecem à esfera da ilusão e permitem a transição do bebê "de um estado em que este está fundido com a mãe para um estado em que está em relação com ela como algo externo e separado" (Winnicott, 1975b, p. 30). Essa transição, contudo, tem continuidade no brincar da criança e nas experiências do adulto com a arte, a religião, o viver imaginativo e o trabalho criador.

O paradoxo como elemento de sustentação da concepção de Winnicott sobre o espaço potencial tem desdobramentos que interessam à configuração de uma teoria clínicopsicológica que busque escapar do "psicologismo". Um primeiro desdobramento diz respeito à abertura para imaginar os primórdios do desenvolvimento infantil como resultando na constituição de um sujeito para quem a consistência do real ou do mundo externo dependeu da possibilidade de criá-lo ali onde ele lhe foi adequadamente apresentado. Na contrapartida, o sentimento de ser e a esperança de uma vida criativa sustenta-se no trabalho de experimentação de coisas e pessoas que se apresentam para a criança. ${ }^{5}$

\footnotetext{
${ }^{3}$ À tarefa de manter mundo externo e interno separados não deve ser atribuído um caráter universal. Ela parece definir, de modo pertinente, um intento do homem moderno, ocidental.

${ }^{4}$ A universalidade desse lugar da mãe como cuidadora pode ser questionada, tanto em relação às diferenças na história da cultura ocidental, quanto em relação às diferenças entre culturas. Winnicott parece conceber uma universalidade do lugar e do papel da mãe a partir do modelo familiar nuclear, ocidental e moderno.

${ }^{5}$ A posição de Hannah Arendt sobre a criança guarda semelhanças com esta posição de Winnicott. Para Arendt, a esfera da vida privada, familiar, é a esfera do cuidado e da proteção para que a criança possa crescer e se desenvolver. A educação escolar,
} 
Outro desdobramento refere-se à necessidade de sustentar o paradoxo que se estende dos objetos transicionais às experiências culturais como aquilo que, a um só tempo, une e separa, descrevendo, em termos psicológicos, a singularidade do indivíduo como criador e criatura da cultura na qual ele existe. Nas palavras de Winnicott:

Interessa-me, contudo, como tema paralelo, o fato de que em nenhum campo cultural é possivel ser original, exceto numa base de tradição. Inversamente, aqueles que nos oferecem uma contribuição cultural jamais se repetem, exceto como citação deliberada, sendo o plágio o pecado imperdoável do campo cultural. A integração entre a originalidade e a aceitação da tradição como base da inventividade parece-me apenas mais um exemplo, e um exemplo emocionante, da ação recíproca entre separação e união (Winnicott, 1975a, p. 138).

A experimentação no espaço potencial é, segundo Winnicott, constitutiva do viver criativo dos indivíduos e vital para a "continuidade da raça humana que trascende a existência pessoal" (1975a, p. 139). Da confiança no ambiente e sua fidedignidade dependem, neste ponto de vista, as experiências no espaço transicional que singularizam o indivíduo por meio da apropriação e criação da cultura. Diz Winnicott:

O espaço potencial entre o bebê e a mãe, entre a criança e a família, entre o indivíduo e a sociedade ou o mundo, depende da experiência que conduz à confiança. Pode ser visto como sagrado para o indivíduo, porque é aí que este experimenta o viver criativo. (1975a, p. 142).

Uma ambiência psicossocial invasiva e pouco confiável rouba a oportuindade de experimentação no espaço potencial, exigindo da criança um padrão reativo de ação e conduzindo-a à adaptação. Para Winnicott, viver é sinônimo de criar; adaptar-se pode ser, por isso, contrário ao viver, remetendo à interrogação sobre a qualidade do viver em contrapartida à mera exigência de responder convenientemente às demandas de um ambiente psicossocial. Interrogação que convoca a clínica psicoterápica a uma revisão crítica de suas finalidades "curativas". Diz o autor:

Para nós é de suma importância reconhecer abertamente que a ausência de doença psiconeurótica pode ser saúde, mas não é vida. Os pacientes psicóticos que pairam permanentemente entre o viver e o não viver, forçam-nos a encarar esse problema, problema que realmente é próprio, não dos psiconeuróticos, mas de todos os seres humanos. (Winnicott, 1975a, p. 139).

sendo da esfera pública, faz a passagem da criança para esta esfera e deve se responsabilizar tanto pela criança quanto pelo mundo. Porém, é possível inferir que tanto para Winnicott quanto para Arendt, o cuidado com a criança enseja, sempre, a questão, para os adultos, sobre como apresentar o mundo para aquele que chega (Arendt, 1979). 
Uma pesquisa exploratória realizada em 1999 junto ao Serviço de Aconselhamento Psicológico (SAP) do Instituto de Psicologia da Universidade de São Paulo ${ }^{6}$ suscitou um conjunto de interrogações sobre como responder, na esfera da psicoterapia, ao sofrimento derivado das dificuldades da clientela nas relações de trabalho e no desemprego.

As dificuldades da clientela foram categorizadas em três grandes grupos: o das pessoas que ainda não haviam ingressado no mercado de trabalho, metade delas estudantes de graduação e pós-graduação, para quem as limitações deste mercado aparecem como fonte de ameaça e medo; o das pessoas que se encontravam empregadas e que sofriam as conseqüências das altas taxas de desemprego, tolerando insatisfações no trabalho e, mesmo subemprego, com receio de ficarem, também, desempregadas; o das pessoas desempregadas, que traziam para as sessões de psicoterapia temáticas ligadas às razões do desemprego e às suas conseqüências para si e para os familiares. (Menezes Júnior et al., 1999).

Sobre o modo como as experiências da clientela relativas a trabalho e desemprego eram (e são) acolhidas no SAP, a pesquisa exploratória revelou aspectos importantes. O mais evidente diz respeito ao lugar secundário que trabalho e desemprego ocupam nas fichas de identificação e nos relatórios elaborados pelos estagiários sobre a clientela e os processos psicoterápicos de cada um. A referência a esses "temas" era de tal maneira lacunar e lacônica nos registros escritos do Serviço, que os estagiários-pesquisadores apelaram para a rememoração de seus próprios atendimentos passados, concluindo que entendiam o desemprego, "quando trazido no processo psicoterápico, como um pano de fundo ou como uma circunstância na qual a dinâmica e os conflitos psicológicos apareciam em sua singularidade" (Sato \& Schmidt, 2001). Esses mesmos estagiários-pesquisadores ao indagarem seus colegas sobre seus atendimentos a pessoas com queixas relacionadas ao trabalho e ao desemprego - inicialmente através de um questionário e depois através de uma entrevista - notaram o desinteresse e a não compreensão da relevância do tema para a clínica psicológica. E, ao concluirem o relato da pesquisa, elencam uma série de perguntas por responder:

...pudemos perceber como os problemas relacionados ao mundo do trabalho vêm afetando o indivíduo e de que maneira eles emergem. Mas muitas questões ficaram sem respostas visto que nos parece que esse problema não tem sido tratado com atenção. A dificuldade que os estagiários tiveram para lembrar dos casos é uma das provas disso. Portanto, ficam perguntas para serem respondidas por aqueles que estarão atendendo outros casos na clínica: as queixas dos clientes sobre condições de trabalho ou sobre o problema do desemprego têm sido acolhidas adequadamente?

De que forma as dificuldades de lidar com essas situações referentes ao mundo do trabalho chegam até o serviço? Como são acolhidas estas demandas? De que maneira elas interferem no andamento das sessões? Será que seria necessário organizar um serviço na área da Psicologia voltado especialmente para essa questão?

Em que grau aquele que atende leva em consideração os determinantes sociais, além de apenas enxergar as questões individuais do cliente? Será que esse problema se dá devido

\footnotetext{
${ }^{6}$ No contexto de uma experiência de integração do Serviço de Aconselhamento Psicológico (SAP) e do Centro de Psicologia Aplicada ao Trabalho (CPAT) do IPUSP, alunos de graduação das disciplinas Aconselhamento Psicológico II e III e Seleção Profissonal I e II realizaram estágio investigativo sobre os modos como queixas relacionadas ao desemprego e ao trabalho apareciam e eram acolhidas na prática clínica do SAP. A pesquisa está relatada em Menezes Júnior et al. (1999). Referências à mesma pesquisa aparecem em Sato \& Schmidt (2001).
} 
à sensação de incapacidade do psicólogo de atuar diretamente na sociedade, numa relação individual? (Menezes Júnior et al., 1999).

Essas perguntas, às quais se pode acrescentar aquela sobre a relação entre o modo como o indivíduo percebe o seu desemprego e o tipo de ajuda que ele procura, configuram um vasto campo de pesquisa teórica e empírica.

Seguindo a sugestão de Geertz para o enfrentamento da visão estratigráfica, aqui responsável pela separação entre mundo do trabalho e clínica psicoterápica, e tomando como suporte a clínica praticada por Winnicott, busca-se seguir a trilha do questionamento aberto pelos estagiários-pesquisadores sobre a possibilidade de acolhimento das experiências de solidão, desenraizamento, desalojamento e desesperança (ou falência da confinça no ambiente como solo de um viver criativo), advindas das frustrações no trabalho ou do desemprego, na esfera da psicoterapia.

\section{IV}

Das inúmeras perguntas lançadas pelos alunos por ocasião da experiência inaugural de colaboração entre o CPAT e SAP, todas interligadas e de grande relevância, algumas seguem sendo investigadas por grupos que atualmente estagiam no CPAT sob coordenação da professora Leny Sato. Um grupo de estagiários-pesquisadores quer, neste momento, compreender dimensões das redes que ligam mundo do trabalho e busca de ajuda psicológica entrevistando uma parte da clientela que procura o SAP nos dias de Plantão Psicológico. Tendo criado um dispositivo que permite às pessoas manifestarem seu interesse espontâneo de participar da pesquisa, os alunos supreenderam-se com o elevado número daqueles que se apresentaram. Embora as entrevistas não tenham ainda começado e as motivações para a participação não tenham ainda se explicitado, é interessante pontuar esta disposição para tratar do assunto e colaborar com uma pesquisa por parte da clientela.

Este preâmbulo tem o propósito de indicar um contraste aparente entre o interesse da clientela em oferecer sua experiência como matéria para uma reflexão (e uma ação) sobre os problemas do trabalho e do desemprego e o relativo alheamento da atividade clínica praticada no SAP em relação à mesma problemática.

Parece, então, que ao pretender acolher, de modo refletido, a clientela que procura ajuda psicológica em decorrência de insatisfação no trabalho ou do desemprego, aqueles psicólogos e estagiários envolvidos no atendimento têm como tarefa de partida situar-se em relação à sua pretensão de acolher, ao mundo do trabalho e à clientela, como condição para a criação de um espaço de escuta qualificado. Com isso se quer dizer algo relativamente simples e até corriqueiro para a prática clínica, ou seja, que o setting psicoterapêutico configura-se também pela presença do psicoterapeuta e sua presença traz à cena atitudes, valores, modos de sentir e de pensar que constituem a própria qualidade da acolhida e da escuta que ele propicia. Trata-se, aqui, de uma presentificação de valores, atitudes, sentimentos, preconceitos, visões sobre o trabalho e o desemprego, bem como sobre aqueles que vivem as vicissitudes de sua trajetória nesse universo.

Grosseiramente, é possível identificar duas posições polares que ora tomam a experiência do cliente desempregado ou com dificuldades no trabalho como fruto de peculiaridades psicológicas do indivíduo - dinâmica da personalidade, problemas 
motivacionais, conflitos inconscientes, bloqueios emocionais, entre outros -, ora como fruto dos determinantes sócio-econômicos que tornam o indivíduo " mais uma vítima do sistema". Situar-se na tensão entre essas polaridades pode ser útil, embora difícil, quando se trata de responder à complexidade do que vive a clientela que, também se apresenta, muitas vezes, fazendo uso dessas figuras polares: culpada pela sua situação, vitimizada pela situação.

Situar-se é um processo, não se trata de alguma coisa que se conquiste de uma vez por todas e pode ser o ponto organizador de uma ajuda psicológica voltada para o universo do trabalho e do desemprego.

O recurso à clínica winnicottiana pode ser precisoso para, por analogia, sustentar esta posição, por parte do psicoterapeuta, não de repouso, mas de tensão entre as polaridades mundo externo/mundo interno, a partir da qual a interrogação sobre quem se é (ou sobre como eu, indivíduo em crise, estou implicado na situação de vida em que me encontro) torna-se indissociável da interrogação sobre onde se está. Ou seja, para o psicoterapeuta significa poder sustentar e, mesmo facilitar, que o cliente interrogue-se a si mesmo, interrogando, ao mesmo tempo, o mundo em que se move.

Uma vinheta clínica pode auxiliar na explicitação da idéia acima exposta.

Um estagiário de quinto ano atendeu num Plantão Psicológico uma cliente que estava bastante angustiada e assustada com o fato de ter rompido relações de trabalho e pessoais com uma tia. Essa moça tinha vindo do interior para morar com a tia, num bairro pobre e periférico de São Paulo, onde a última mantinha um restaurante no qual a moça foi trabalhar. Sem vínculos empregatícios, morando na casa dos parentes e tendo-os como única referência na cidade, a moça reclama direitos trabalhistas referentes a salário e férias e é brutalmente repelida pela tia, que passa, inclusive, a ameaçá-la de morte caso siga com o propósito de processá-la judicialmente. A moça traz sonhos de muita agressividade, nos quais ora persegue, ora é perseguida.

Na supervisão em grupo do atendimento, duas linhas de interpretação e de sugestão de como o estagiário se posicionar apareceram inicialmente: uma, apontava na direção de apoiá-la no sentido de prosseguir com o processo contra a tia, pois tratava-se de um direito garantido por lei, do qual ela não devia abrir mão e a hipótese era de que a psicoterapia poderia fortalecê-la para enfrentar as ameaças e "chantagens" da tia; outra, delineava a conveniência de um trabalho fundamentado na compreensão dos sentimentos e conflitos subjascentes à crise desencadeada pela oposição da moça à tia, de tal modo que a moça pudesse lidar melhor com sua agressividade, insegurança e dependência.

O estagiário que realizava o atendimento mostrou-se insatisfeito com as sugestões e reiterava, a todo momento, que estava muito preocupado com a moça, avaliando que ela corria sério risco de vida, pois a tia e as pessoas a ela ligadas, pelo que tudo indicava, eram "bandidas", possuiam armas e "não brincavam em serviço".

A supervisão encaminhou-se, então, para uma tentativa de permitir que o estagiário se situasse em relação à demanda da cliente e em relação à realidade da situação que ela havia exposto. Nesse processo, o estagiário esclarece que não acredita que o sistema judiciário venha a proteger a moça e, embora reconhecendo o seu direito de processar a tia, fica claro que sua condição de vida exige que se pondere que a rede familiar e de vizinhança, embora "bandida", representa um suporte material e afetivo do qual ela não pode abrir mão muito simplismente. Ou seja, além dessa rede familiar, a moça não tem com quem contar. Suas "fantasias" de perseguição e abandono estão ancoradas numa percepção quase subliminar dos riscos que efetivamente corre. Seu conflito entre lutar pelos seus direitos, rompendo relações de solidariedade com o grupo familiar, e tentar uma reconciliação com a tia, recuperando uma certa segurança, submetendo-se, contudo, à injustiça e indignidade impostas pela lógica daquela relação, dependia não de uma avaliação sobre o que era correto, juridicamente legal, 
ou sobre o que era saudável, bom do ponto de vista de seu conforto psicológico. Dependia, pensou o estagiário, da possibilidade dessa moça situar-se em relação a quem era ela e onde ela estava (no sentido de perceber o que era vital no seu entorno para sustentar permanências ou deslocamentos no modo como ela se percebia e agia, no presente e como projeto).

Com esse exemplo, sumariado de maneira que muitos detalhes e desdobramentos da rica discussão havida não puderam ser contemplados, quer se mostrar a importância dos processos de situar-se do psicoterapeuta como condição para que ele mesmo se apresente como presença capaz de sustentar um processo de situar-se por parte da cliente.

O trabalho constitui-se em modos de coexistência que sustentam identidades, jeitos de ser e existir num mundo compartilhado. É vital no sentido estrito de ser garantia de sobrevivência mas, mais largamente, é vital como criação do mundo, como transformação da terra em lugar habitável, como modo de enfrentar a inospitalidade da terra.

As experiências de desenraizamento, solidão, desamparo e desesperança fazem pensar na condição existencial daqueles que procuram atendimento psicológico em decorrência de insatisfações no trabalho ou do desemprego.

É possível imaginar, e mesmo acessar? ${ }^{7}$ no que concerne à clientela, uma gama de maneiras de entender a situação vivida em relação ao universo de trabalho e sua conexão com a busca de psicoterapia. As representações da clientela sobre o desemprego conjugadas à psicoterapia devem ser objeto de estudos mais aprofundados. A ausência de dados mais sistemáticos sobre esse público não impede, contudo, que se prossiga, mais um pouco, explorando teoricamente as possibilidades da psicoterapia como espaço de acolhimento para tal clientela.

Algo diferente e complementar ao dito no item anterior avizinha-se como tema a percorrer: a psicoterpia como morada, repouso e suporte, respondendo à situação existencial de desenraizamento, solidão, desamparo e desesperança relacionada às insatisfações no trabalho e ao desemprego.

No artigo Ética, saúde e práticas alternativas, Luís Cláudio M. Figueiredo (1996) faz referência a um "habitar sereno e confiado" como condição de saúde e o faz num sentido muito próximo daquele que Winnicott atribui ao viver (criativo). Ele escreve:

o habitar sereno e confiado é também a condição do pensar, do representar, do brincar e do experimentar, exatamente porque o abrigo da casa nos dispensa qualquer representação: também nesse sentido a casa liberta (Figueiredo, 1996, p. 47).

E, fazendo uma referência direta a Winnicott, Kohut (1988) e Bollas (1992), que tematizam as experiências construtivas de um cuidador que cuida da criança como se ela fizesse parte dele mesmo, conclui que:

\footnotetext{
${ }^{7}$ A pesquisa exploratória sobre as queixas dos clientes que buscavam atendimento psicológico no SAP possibilitou a sondagem de algumas maneiras de tematizar as razões do desemprego que incluiam desde aspectos relacionados a características da pessoa até análises sobre a situação sócio-econômica do país.
} 
A obra desses autores mostram, também, que experiências dessa natureza, continuam ocorrendo durante todo o processo normal de desenvolvimento, ao longo de toda a vida. Há sempre ocasiões em que partes do ambiente social e físico nos oferecem gratuitamente - um certo resgate dessa relação primária, com o entorno (Figueiredo, 1996, p. 48).

A analogia que se quer aqui explorar é essa da relação psicoterápica como uma relação de cuidado pautada pelo desejo de ser morada. Como parte de um ambiente social e físico que se apresenta, para a experiência da clientela, como ameaçador, adverso, inóspito, o setting do atendimento em uma instituição como o SAP pode se oferecer como contraponto: lugar de repouso e suporte para o pensar, o brincar, o representar, o experimentar.

Talvez seja preciso insistir que não se está com isso querendo afirmar que, por esta via, resolve-se a grave questão do trabalho alienado e do desemprego. Sugere-se, isto sim, que, estando a porta do SAP aberta para receber uma clientela que sofre em conseqüência do trabalho e do desemprego, prepare-se, da melhor forma possível, a casa em que se recebe.

Essa busca de constituição de um lugar imaginado, desejável, digno para a psicoterapia, no contexto das discussões e ações em torno do trabalho e do desemprego, ao se restringir modestamente à função de acolhimento, roça-se a dimensão, nada modesta, do existir no mundo, com outros. Nas palavras de Luís Cláudio Figueiredo:

sustentar-se nesse existir no mundo - e só assim se existe - exige um espaço de separação e recolhimento, de proteção, que não encerre o existente em uma clausura, mas lhe ofereça uma abertura limitada (portas e janelas) a partir da qual sejam possíveis encontros - saídas e entradas - em que se reduzam os riscos dos "maus encontros", dos encontros destrutivos e traumáticos (Figueiredo, 1996, p. 45).

Talvez a psicoterapia possa ocupar, como uma referência entre outras possíveis, esse espaço de separação e recolhimento, esse lugar de repouso e suporte, num momento de perigo e risco para uma clientela que se encontra desalojada.

Clinical psychology, work, and unemployment: theoretical concerns

This article concerns the separation between work psychology and clinic psychology, pointing out the necessity of articulation of this two areas to deal with the psychological suffering wich cames from the dificulties in work and unemployment. Explores concepts of Winnicott's theory to creat an pshychological practice in syntony with the loneliness, abandonment and desillusionment originated by work and unemployment.

Keywords: phychological clinic, work, unemployment, interdisciplinarity, Winnicott.

Endereço para contato com a autora: liana@macbbs.com.br 


\section{Referências Bibliográficas}

Arendt, H. (1979). A crise na educação. In Entre o passado e o futuro (pp. 221-247). São Paulo: Perspectiva.

Bollas, C. (1992). A sombra do objeto. Rio de Janeiro: Imago.

Figueiredo, L. C. M. (1996). Ética, saúde e práticas alternativas. In Revisitando as psicologias: da epistemologia à ética das práticas e discursos psicológicos (pp. 41-73). São Paulo: Educ. Petrópolis: Vozes.

Geertz, C. (1989). O impacto do conceito de cultura sobre o conceito de homem. In A interpretação das culturas (pp. 45-66). Rio de Janeiro: LTC.

Luz, R. (1990). Winnicott e a experiência artística. Psi: Revista Brasileira de Psicanálise. Associação Brasileira de Psicanálise. 24 (2), 179-190.

Kohut, H. (1988). A restauração do self. Rio de Janeiro: Imago.

Menezes Júnior, A., Ramos, C. H. G., Fernandes, D. L., Ruzzante, G., Koga, R., Oliveira Neto, S. \& Oliveira, T. A. (1999). O problema do desemprego - como ele é trazido até o Serviço de Aconselhamento Psicológico do Instituto de Psicologia da USP, São Paulo. [apostila]

Sato, L. \& Schmidt, M. L. S. (2001). Atendimento clínico e desemprego: uma experiência de integração. Anais do VIII Colóquio Internacional de Sociologia Clínica e Psicossociologia. Belo Horizonte.

Winnicott, D. W. (1975a). A localização da experiência cultural. In O brincar e a realidade (pp. 133143). Rio de Janeiro: Imago.

Winnicott, D. W. (1975b). Objetos transicionais e fenômenos transicionais. In O brincar e a realidade (pp. 13-44). Rio de Janeiro: Imago. 